http://dx.doi.org/10.12795/RAA.2011.i01.06

\title{
ETNOCENTRISMO, RACISMO Y RELATIVISMO EN UN PAÍS “CIVIL": ITALIA AL INICIO DEL TERCER MILENIO
}

\section{AMALIA SIGNORELLI \\ Università La Sapienza di Roma}

\section{Resumen.}

De ser un país de antigua y abundante emigración, Italia pasó a convertirse desde finales de la década de los setenta en un país de inmigración. Treinta años después, se puede constatar que en Italia predomina una opinión pública racista. ¿De dónde surge este racismo? Tomando como referencia los estudios de los antropólogos italianos Ernesto de Martino, Carlo Tullio Altan y Vittorio Lanternari, en este artículo se profundiza en el estatuto teórico de los conceptos de etnocentrismo de actitud, etnocentrismo ideológico y etnocentrismo crítico, y en la relación que se establece entre estos, el racismo y el relativismo. Por último, se consideran las aporías del relativismo pero también su función irrenunciable para garantizar, como ha señalado Geertz, "un mínimo de decencia” en las relaciones entre los seres humanos.

Palabras clave: Migraciones, etnocentrismo de actitud, etnocentrismo ideológico, etnocentrismo crítico, relativismo, Italia.

\section{Abstract.}

Having migrated for one and half a century to Europe, the Americas and Australia, in the '70s of the XXth Century Italians discovered that their country was a destination 
for people coming from Africa, Asia, South America. Now there are in Italy about five million of foreign people; and the majority of italian people seem to have developed a racist aptitude. Referring to V.Lanternari's, C.TullioAltan's and E. de Martino's studies, this paper discuss the concepts of aptitudinal ethnocentrism, ideological ethnocentrism, critical ethnocentrism and their connections with racism. In the end relativism is discussed both in its theoretic and moral contents.

Keywords: Migrations, aptitudinal ethnocentrism, ideological ethnocentrism, critical ethnocentrism, racism, relativism, Italy.

La situación que se ha ido creando en Italia desde finales de los años setenta ofrece interesantes elementos para quien desee reflexionar sobre las nuevas topografías de la cultura. En esos años adquiere consistencia un fenómeno absolutamente inédito para la sociedad italiana: la llegada de inmigrantes procedentes de los países llamados extracomunitarios, externos a la primero denominada Comunidad Económica Europea y luego Unión Europea. De ser un país de antigua y abundante emigración, Italia se ha visto transformada en un país receptor de inmigración; una inmigración dotada además de algunos rasgos característicos. Llegan a Italia personas y grupos procedentes de todos los continentes: filipinos, caboverdianos, senegaleses, marroquíes, peruanos, polacos, rumanos, ucranios, ghaneses, albaneses y nigerianos. Actualmente se calcula que en Italia hay más de 4 millones de inmigrantes entre los clandestinos y quienes poseen documentación, una cantidad que constituye un porcentaje cercano al 5\% con respecto a la población italiana y que corresponde a la media europea. Los que emigran a Italia pertenecen a más de 20 nacionalidades. Otra característica destacada es que Italia, aún siendo un país rico, dispone de un sistema productivo estructuralmente incapaz de garantizar la plena ocupación a los italianos y todavía presenta emigración autóctona.

La inmigración extranjera en Italia encuentra ocupación fundamentalmente en los servicios a las personas y en el terciario comercial y para el tiempo libre, y secundariamente en la industria y en la agricultura. También por esta razón es una inmigración caracterizada por una fuerte presencia de mujeres que emigran solas para emplearse como trabajadoras domésticas y como cuidadoras de ancianos.

La multiplicidad de culturas que presentan los inmigrantes es muy grande. Sin embargo, siguiendo a Balandier, hay que destacar que ellos no son portadores de culturas originarias, nativas o auténticas. Muchos grupos proceden de países con un pasado colonial o postcolonial, otros de países con un pasado socialista. Es un hecho que las migraciones contemporáneas han invertido sólo aparentemente el escenario tradicional de los procesos llamados "de aculturación" en la edad colonial: ya no se mueven los "aculturadores", sino los "aculturados"; la relación numérica entre unos y otros en los 
lugares de llegada se encuentra invertida, los "nativos" occidentales son la mayoría mientras que los nuevos llegados la minoría; los que en el régimen colonial ocupaban el papel de los conquistados, sometidos u oprimidos parece que ahora hayan adquirido un status diferente: son "libres": seres humanos que por "libre" decisión han dejado su tierra y han venido a los países "occidentales". Es oportuno aclarar, no obstante, que las situaciones que se presentan no se pueden reducir a una simple inversión de la condición colonial y que la situación de los que proceden de Europa del Este no es tampoco reducible a un paso lineal desde condiciones de vida propias de un país socialista a condiciones de vida de un país capitalista.

Cada inmigrante y cada grupo de inmigrantes lleva consigo un patrimonio cultural complejo del cual es parte, en casi todos los grupos, lo que podríamos llamar, con Appadurai y Canclini, "globalización imaginada", es decir un proceso de contacto y circulación cultural ampliamente mediado por las nuevas tecnologías de la comunicación a distancia. Es un hecho conocido y continuamente confirmado por el trabajo de campo que los inmigrantes llegan con una idea de Italia bien estructurada; así, una parte consistente del trabajo que tienen que hacer, por lo menos en el primer período de su estancia, es adecuar sus expectativas a la experiencia y su experiencia a las expectativas.

Frente a esta multiplicidad de culturas emigradas que conviviendo e interactuando en el mismo espacio-tiempo histórico producen otras formas culturales, se encuentran los italianos con toda su complejidad histórico-cultural, caracterizada por estratificaciones de sexo, clase, religión y hecha aún más compleja en relación con los inmigrantes por las expectativas, los estereotipos y los prejuicios. Son unos italianos que no constituyen un grupo homogéneo: se pueden distinguir bastante bien los de fe católica, en principio abiertos a la acogida aunque a menudo bajo una forma de paternalismo caritativo; los italianos "de izquierda" (Italia es el país que durante décadas tuvo el Partido Comunista más fuerte en Occidente) que adoptan una óptica igualitaria y emancipadora; y, finalmente, los italianos conservadores y "de derecha", nostálgicos del Imperio y que reivindican lo que consideran una superioridad incuestionable. A pesar de ello, es fácil observar entre los italianos marcadas distancias entre sus afirmaciones y sus prácticas cotidianas; un hecho bien conocido por quienes realizan estudios de campo.

A qué resultados conducirá a medio plazo este agitado proceso de contactos y de mezclas es demasiado pronto para preverlo; lo que se puede observar es que en el corto plazo una parte consistente de los italianos ha demostrado pertenecer al área de los convencidos de su propia superioridad, animados por la desconfianza y el desprecio hacia los inmigrantes e inclinados a considerarles como un "mal necesario"; tolerables sólo si son asignados a tareas concretas y relegados en espacios bien identificados y circunscritos. Que esta orientación sea mayoritaria lo sugiere el resultado de las elecciones políticas de la primavera de 2008, que han respaldado al gobierno de Silvio Berlusconi y su coalición. 
Este gobierno, que se define de centro-derecha, ha adoptado una serie de medidas que empeoran las condiciones de llegada y de vida de los inmigrantes extranjeros en Italia. Algunas de ellas, como considerar delito penal la falta de permiso de residencia incluso si el inmigrante posee una visa de turista caducada, han recibido la censura del parlamento Europeo, al haber sido consideradas medidas transgresoras de los derechos humanos; otras, como la propuesta más reciente de instituir en la escuela elemental clases separadas para los hijos de los inmigrantes, presentan un parecido no casual con las más clásicas políticas de apartheid. Sin embargo, la opinión pública, o por lo menos una parte (¿mayoritaria?) de ella, parece encontrarse de acuerdo con estas medidas: en la actualidad se están multiplicando en las ciudades italianas graves episodios de violencia gratuita hacia personas que tienen como única culpa la de parecer diferentes: cócteles molotov arrojados en los campos de los romas, personas de piel negra o con perfiles orientales atacadas y golpeadas en las paradas de los autobuses, un joven negro golpeado a muerte por dos italianos, padre e hijo, por haber robado un paquete de galletas en su tienda de comestibles...

La antropóloga italiana A. M. Rivera considera que en Italia es mayoritaria la opinión pública racista y los hechos que ocurren cada día parecen darle la razón.

Se han activado en Italia numerosas posturas en contra del relativismo cultural. Esta condena procede de una voz muy influyente: el Papa Benedicto XVI, que incide sistemáticamente en este asunto con tonos de intransigencia extrema. Su postura encuentra seguimiento entre intelectuales y políticos, tiene importantes resonancias en los medios de comunicación de masas y se añade a las posiciones que teorizan el choque de civilizaciones o la existencia de países-canalla.

Esta situación plantea algunas cuestiones cruciales acerca de las dinámicas culturales, interrogantes en cierto sentido clásicos ya que, aunque la antropología se enfrenta a ellas "desde siempre", parece que no hayan encontrado todavía respuestas satisfactorias. Vuelvo a proponerlas con la esperanza de solicitar sugerencias útiles.

¿Desde donde brota el racismo? En virtud de su historia, remota y reciente, Italia parecía hasta hace poco un país mínimamente inclinado a adoptar posiciones de este tipo; evidentemente se trataba de una actitud aparente y engañosa.

Por parte de la teoría antropológica, el racismo se considera como una forma extrema y fuertemente ideológica de etnocentrismo.

Ya Sumner, quien inventó el término, consideraba el etnocentrismo como un síndrome constituyente de la condición humana, indispensable en el proceso de instauración tanto de la cohesión interna de un grupo como de la competencia entre grupos distintos. Esta tesis reenvía, a su vez, a otra que los antropólogos a menudo han aceptado como un supuesto incuestionable: la tesis de que el extranjero activa con su mera presencia la 
desconfianza, cuando no el temor, por parte del grupo con el cual entra en contacto. Así, la hostilidad hacia él siempre estaría presente, aún cuando sea mantenida a raya y reducida a un eufemismo en nombre de otros intereses y necesidades. Aún más: la simple noción de la existencia del "otro", de vecinos diferentes, estaría en el origen de la autovaloración que cada grupo elabora de sí mismo fundándola en la devaluación y la inferioridad de los demás, por lo menos en el plan onomástico (aquí siempre se citan ejemplos de los nombres tribales que significan "nosotros, los hombres" en oposición a los devaluantes epítetos asignados a los “otros": los bárbaros, los no-hombres, etc.) Lanternari habla del "prejuicio etnocéntrico de superioridad, ya presente como actitud psicológica desde los primeros estadios culturales" (Lanternari, 1979:10). Una psicoanalista italiana, F. Ongaro Basaglia, considera este terror inspirado por el Otro como una condición humana originaria, primordial: "Mientras que la vida se lleve a cabo bajo la amenaza de la naturaleza incontrolada, el hombre está rodeado por fuerzas oscuras y enemigas, de las cuales lo desconocido y lo ajeno son parte: si el hombre representa una amenaza para el hombre, su supervivencia se funda en la eliminación de quien es considerado diferente, desconocido, amenazante o simplemente de quien se presenta en el horizonte de su territorio. La identificación del extraño como enemigo es automática y el enemigo se elimina para no ser eliminado: quien mata consigue vivir" (Ongaro Basaglia, 1978:748).

Las observaciones de Malinowski acerca de las formas de agresión entre tribus sugieren que los etnocentrismos ideológicos son construcciones culturales en las cuales "el prejuicio etnocéntrico de superioridad [...] asume la función de una ideología de poder abrumadora [...] en relación a condiciones generales en las sociedades políticamente organizadas, que tienden hacia guerras de conquista territorial y política" (Lanternari, 1979:10).

De manera aún más neta y definitiva E. Leach afirma “... el tipo de etnocentrismo que cuenta realmente y que alcanza su apogeo en la guerra santa para preservar la pureza y la integridad de 'nuestro grupo', de 'nuestro pueblo' (con la correspondiente masacre y explotación a gran escala de los demás), extrae siempre sus símbolos de las directas experiencias privadas del 'yo': nutrición/defecación, limpieza/suciedad, erotismo/ascetismo, procreación/esterilidad" (Leach, 1978:969). A este propósito, C. Tullio Altan, en un importante ensayo, enseñó como la transformación en símbolos, es decir en imágenes de valor, de los elementos de la realidad objeto de los etnocentrismos actitudinales, constituye uno de los principales procesos de elaboración de las ideologías etnocéntricas: se aplica a la secuencia completa de procreación-sangre-linaje-raza superior (Tullio Altan, 1992).

El etnocentrismo ideológico es explícito, formalizado, racionalizado y racionalizador de cualquier tipo de agresión y de opresión también cuando se presenta en las formas amistosas de una tarea de civilización de los bárbaros o como una carga para el hombre blanco, que no puede abstenerse de adoptarla en nombre de su superioridad; o también cuando asume las apariencias generosas y caritativas de lo que llamamos ayuda al 
desarrollo (Le Monde Diplomatique, 2008). Ciertamente, esta necesidad de superar el miedo al otro atacándole encuentra su complemento en la necesidad de identificación y de autoidentificación a través de la pertenencia a un grupo. Sigue diciendo Lanternari: "... la capacidad de considerar como datos naturales, obvios y universales, a los modelos y a las categorías expresivas de la propia cultura coincide con una necesidad de identificación inherente a la personalidad humana en cuanto tal" (Lanternari: 1979:23), y recupera de Devereux la noción de una "necesidad-sentimiento de identidad, que se encuentra en la base de las más genéricas formas de etnocentrismo de tipo actitudinal" (Lanternari: 1979:75).

Sin embargo, la producción de etnocentrismos no se puede deducir mecánicamente sólo por la necesidad de identidad y por el miedo al extranjero y al desconocido; desde mi punto de vista, tampoco se puede deducir por la exigencia consciente e instrumental de legitimar la agresión por parte de quien es promotor de la misma. En particular, si fuera así, es decir si las ideologías construidas a partir de los etnocentrismos fuesen solamente el producto de una estrategia de legitimación puesta en marcha por élites agresivas y predatorias, esta explicación no aclararía las adhesiones masivas que las varias formulaciones ideológicas del etnocentrismo agresivo consiguen tan a menudo.

Un elemento de profundización útil lo proporciona la noción de etnocentrismo actitudinal. Lanternari distingue entre etnocentrismos actitudinales y etnocentrismos ideológicos, y considera como asunto de los primeros todas aquellas formas de estar, de hacer, de decir, de mirar al mundo, a la experiencia y a la relación con el mundo y con los demás que componen la cotidianeidad de los miembros de cada grupo; formas que, para ser profundamente interiorizadas e incluso incorporadas por los individuos se viven con muy escasa conciencia como modos de ser al mismo tiempo naturales y universales; debido a ello no se tolera su puesta en duda, su sumisión a crítica o simplemente su comparación con modos "otros" de vivir. Lanternari construyó con finura el mapa de los etnocentrismo actitudinales, desde los etnocentrismos que se insertan en la educación de los sentidos, en la disciplina de los cuerpos mediante la adquisición de técnicas posturales, cinéticas, comunicativas, en la adecuación de los comportamientos y de las reacciones emotivas a las reglas de etiqueta o en la adquisición de familiaridad con un ambiente determinado. Una parte significativa de los patrimonios culturales individuales y colectivos, progresivamente asimilada en el proceso de enculturación y socialización, es vivida subjetivamente como una verdadera "segunda naturaleza". En los etnocentrismos actitudinales Lanternari inscribe también el etnocentrismo lingüístico y el epistemológico, que define como "el más oculto" porque es percibido y reconocido con menor conciencia por quien lo practica.

Los etnocentrismos actitudinales quedan, a su juicio, como "un problema abierto", por su persistencia de larga duración y porque, a causa de su naturaleza inconsciente e irreflexiva, 
refutarlos o controlarlos resulta aún más difícil que en el caso de los etnocentrismos ideológicos.

Aún teniendo distinta naturaleza, los etnocentrismos actitudinales y los ideológicos no carecen de conexiones profundas. Lanternari frecuentemente subraya que es una operación difícil e incluso arbitraria "escindir los etnocentrismos vinculados a un origen y a una identidad estrechamente racial (étnica) de los etnocentrismos latu sensu, ligados a grupos que se reconocen según identidades sociales de la más variada naturaleza, de tipo cultural, lingüística, religiosa, de descendencia o sexual” (Lanternari, 1986: 43).

Este vínculo entre etnocentrismos actitudinales y etnocentrismos ideológicos es sacado a debate para explicar la constante reproducción de los últimos a pesar de su contenido irracional y moralmente aberrante: los etnocentrismos actitudinales son parte integrante del proceso de construcción de la identidad; ésta, que se funda en los etnocentrismos actitudinales no puede dejar de tener un carácter excluyente y de oposición. En realidad, hay una especie de consenso, tácito algunas veces y explícito otras, sobre el hecho de que la producción de etnocentrismos actitudinales responde a necesidades tanto elementales como universales de la condición humana: la necesidad de seguridad y la necesidad de pertenencia. Por lo tanto, si responde a necesidades universales, la postura etnocéntrica en el nivel actitudinal será también universal e inextirpable, cualesquiera sean los contenidos específicos que en cada caso contiene. Solo quedaría aceptarlos, pues, y vigilar su posible degeneración en etnocentrismos ideológicos.

A pesar de su evidencia, quizás habría que problematizar estas afirmaciones. Una mejor comprobación de la tesis según la cual la hostilidad y la oposición devaluadora son actitudes psicológicas universales e innatas requeriría una confrontación estricta y puntual entre datos antropológicos y conocimientos psicológicos que no puede ser realizada en este lugar. Sin embargo, como antropóloga me valgo de la vieja sugerencia boasiana de acuerdo a la cual en el ámbito cultural "todo puede ser de otra manera".

Alegar el automatismo de la identificación entre lo ajeno y lo enemigo significa no tener en consideración otra actitud-capacidad humana, la curiosidad, que no tuvo un papel secundario en la historia de la humanidad. En el plano psicológico no podría decir si la curiosidad excluye el miedo a lo ajeno y a lo desconocido, aunque en el plano de los comportamientos humanos, individuales y colectivos, a menudo es posible detectar situaciones en las cuales la curiosidad prevalece por encima de la desconfianza y del miedo. Sin querer citar forzosamente alguna autoridad en la materia como María Montessori, quien ha criado niños sabe que un crío, también muy pequeño, que no ha sido traumatizado o influenciado por ideas preconcebidas, manifiesta más curiosidad que miedo frente a personas y situaciones nuevas; sin arriesgarnos a ser acusados de ingenuas identificaciones entre ontogenia y filogenia, habría que buscar en el pasado de la humanidad los testimonios de curiosidad positiva hacia los extranjeros por lo menos 
con la misma atención con la que se investigan las pruebas de la agresividad originaria. Al fin y al cabo, también una revisión superficial de las historias de descubrimientos y conquistas parece sugerir que la agresividad de los nativos hacia los blancos fue más a menudo secundaria que primaria; al contrario, la agresividad de los blancos no estuvo ciertamente alimentada sólo por el miedo a que los nativos amenazaran la validez y la bondad de los usos y costumbres a que ellos mismos se conformaban. No es injustificado pensar que fuese la búsqueda de riquezas y de poder lo que alimentara en la misma medida la agresividad de los blancos (Parias, 2004). Con otras palabras, mientras no es en absoluto mi intención mantener como hipótesis una especie de irrelevancia subjetiva y objetiva, en el contexto de las relaciones humanas y del patrimonio de actitudes y capacidades individuales y colectivas aprendidas en el transcurso de los procesos de enculturación experimentados en el seno de un grupo, me gustaría poner en discusión el supuesto según el cual aquellas actitudes-capacidades son automáticamente vividas por los sujetos a los que pertenecen como constitutivamente inconciliables con las de cualquier otro grupo humano. También deseo cuestionar la idea de que las actitudescapacidades de otros grupos son vividas automáticamente y de modo pre-juicial como una amenaza para las propias. Aparte de la comprobada existencia de la curiosidad humana, se puede observar que todos los grupos conocen alguna forma de división no sólo del trabajo sino del poder, por lo menos de acuerdo a distinciones de sexo y de edad; no es arbitrario sostener como hipótesis que todos y todas aquellos que en el interior del grupo resultan favorecidos en la asignación de los roles y en el disfrute de un status puedan observar, en circunstancias que habría que especificar en cada ocasión, los usos y los sistemas de valor diferentes de los del grupo de pertenencia con esperanza y ya no con miedo. Un cuidadoso análisis etnográfico de casos concretos de aculturación podría producir sorpresas en este sentido.

Finalmente, me gustaría cuestionar la planteada identificación de la identidad individual con la pertenencia a un grupo localizado, circunscrito y “étnicamente" homogéneo. Sé que la casuística que presenta el panorama geopolítico contemporáneo parece ofrecer sólo confirmaciones para esta hipótesis; sin embargo, tal vez sea útil empezar por una exploración histórico-etnográfica que permita evidenciar todos los casos en que la identidad se reconfigura sin conexiones a una localización específica o a una sociedad circunscrita y establemente integrada. Se podría citar, extemporáneamente, en relación al primer caso, a los grupos nómadas, las órdenes religiosas y de caballería de la Edad Media o los barqueros del Volga y los pescadores de las dos orillas del mar Adriático o del Tirreno hasta hace medio siglo; en relación con el segundo caso, aún más extemporáneamente, se pueden recordar todas las compañías y los grupos poco estables y poco estructurados que vivían vagando por Europa desde el principio de la Edad Moderna, aunque sus miembros se reconocían como similares: mercenarios, comerciantes de ferias, cómicos de la comedia del arte y titiriteros, cuadrillas de jornaleros, grupos de marineros y 
ciertamente los clerici vagantes que, nacidos en la Edad Media, todavía prosperan en día de hoy con el nombre de visiting professors o estudiantes Erasmus no solamente en Europa ${ }^{1}$.

Justamente en los movimientos de población, la doble pertenencia y las identidades múltiples y por lo tanto relativamente lábiles presentan una historia larga de siglos, que no ha sido -y no es- sólo una historia de hostilidad, de agresividad, de pérdidas o de ausencias.

Personalmente lo que quería cuestionar no es tanto la necesidad de identificación por parte de los sujetos individuales o colectivos como la limitación de la satisfacción de esta necesidad a un abanico reducido de posibilidades que no reflejan las variaciones de la historia de la condición humana sino que las limitan a los casos de la coyuntura presente. Merece la pena citar en este contexto un concepto de De Martino. Él sugería que las patrias de los seres humanos podrían ser "culturales" además de anagráficas. La cultural es una patria que no ha sido asignada por la suerte, sino elegida de acuerdo a ciertos valores, lo cual ofrece la oportunidad de trascender lo existente y de ir más allá de una situación determinada.

Ciertamente, aceptar la posibilidad de tener muchas patrias y no una es seguramente una posición relativista. Por otra parte, el relativismo, por lo menos metodológico, es como dijo Geertz, una condición que proporciona a la investigación antropológica un mínimo de dignidad.

Sin embargo, si hay una posición absolutamente cargada de aporías es ciertamente la relativista. En la tradición de los estudios italianos, De Martino, aún proponiendo la idea de patria cultural, ha reiterado repetidamente su propia crítica al relativismo de la antropología cultural norteamericana. En su interpretación, el relativismo de los boasianos corre el riesgo de naturalizar a los ethnos más lejanos y no consigue ir más allá de la "pretensión de colocar la cultura occidental «entre» todas las demás, como si fuera posible por el antropólogo contemplar como apátrida todas las demás culturas, en una especie de objetivismo metacultural y metahistórico" (De Martino, 1962: 154).

Salir de este impasse significa pasar del objetivismo a la historización de sí mismos y de la propia cultura. Un paso que no puede ser considerado como realmente dado si no se dispone del valor de asumir todo su alcance cognoscitivo y ético: historizarse significa aceptarse como "centro de evaluación" e "involucrarse en la mediación de la reflexión en el mismo momento en el que [tiene] lugar el encuentro etnográfico" (De Martino, 1962: 166).

1. Me refiero, por ejemplo, a las "colonias" de profesores indios o chinos (aunque hace cincuenta años europeos, especialmente alemanes, de origen judío) en las universidades de EE. UU. Se trata de grupos bien insertados en el país de acogida, disfrutando de sus ventajas y oportunidades, pero que se declaran fuerte y positivamente conectados con el lugar de origen. No es el caso que algunos de estos grupos reivindiquen para sí mismos la definición de "diásporas". 
En las páginas de $E l$ fin del mundo el relativismo cultural vuelve como objeto de una reflexión que nunca se considera agotada: "El peligro del humanismo etnográfico que se despliega en la época de la segunda revolución industrial y de la colonización es el relativismo cultural. Sólo Occidente ha producido un verdadero interés etnológico, en el sentido amplio de comparar sistemáticamente la propia cultura con las otras sincrónicas y ajenas: pero esta comparación no puede llevarse a cabo sino en la perspectiva de un etnocentrismo crítico, en la cual el etnólogo occidental (u occidentalizado) asume la historia de la cultura propia como unidad de medida de las historias culturales ajenas, aunque al mismo tiempo, en el acto de medir, gana conciencia de la prisión histórica y de los límites del propio sistema de medida y se abre a la tarea de una reforma de las mismas categorías de observación de que dispone al principio de la investigación. Sólo colocando de modo crítico y deliberado la historia de Occidente en el centro de la investigación, el etnólogo podrá contribuir a inaugurar una conciencia antropológica más amplia que la enclaustrada en el etnocentrismo dogmático" (De Martino, 1977: 396-7).

En este trasfondo de ideas, De Martino plantea su crítica al relativismo. No es una crítica definitiva; es, más bien, la crítica "nerviosa" de quien sabe tener buenos argumentos pero no el decisivo. Pero tampoco hoy estamos a gusto al enfrentarnos una vez más con las aporías de una postura -la relativista o incluso relativizadora- que nos incomoda como antropólogos tal vez justamente porque no es posible adoptarla como instrumento epistemológico y heurístico sin contar con su contenido ontológico y ético. En la distancia de unas décadas desde las reflexiones de De Martino, desde una perspectiva que puede aprovechar los estudios y reflexiones de Bourdieu, de Wittgenstein y de Winch, de Barnes y de Bloor, pero también de Gellner y de Lukes, de Tullio Altan y de Lanternari, así como de todos los demás que se han ocupado del relativismo etnocéntrico, ¿disponemos hoy de un argumento decisivo en favor o en contra del relativismo?

Como ha hecho recientemente en Italia Francesco Remotti en un escrito que se presenta como una verdadera carta abierta dirigida a Benedicto XVI, frente a todas las posiciones que definen como no natural a los diferentes, tenemos que reivindicar al relativismo su irrenunciable función, su capacidad de garantizar "un mínimo de decencia" a las relaciones entre seres humanos (Remotti, 2008). No podemos retroceder ni un milímetro en esta posición, pero tampoco podemos declararnos satisfechos. Como antropólogos, y por lo que nos compete, tenemos que ir más allá. Una tarea que no es nada fácil. 


\section{REFERENCIAS BIBLIOGRÁFICAS}

DE MARTINO, E. (1962) Furore, simbolo, valore. Milano:Feltrinelli.

DE MARTINO, E. (1977) La fine del mondo. Contributo a una storia delle Apocalissi culturali. Torino: Einaudi.

LANTERNARI, V. (1979) Problema di etnocentrismo e di identitá. Roma: La Goliardica.

LANTERNARI, V. (1986) “Etnocentrismi: dall'attitudine all'ideologi”. En L'incivilimento dei barbari. Bari:Dedalo.

LEACH, E. (1978) Etnocentrismo. En Enciclopedia Einaudi, vol. V. Torino, Einaudi.

LE MONDEDIPLOMATIQUE (2008) Dietro il paravento del sistema umanitario. XV, 8-9, agosto-settembre, pp.9-13.

ONGARO BASAGLIA, F. (1978) Esclusione/integrazione. En Enciclopedia Einaudi, vol. V. Torino: Einaudi.

PARIAS, L. H. (2004) Les explorateurs. Paris: Editions Robert Laffont.

REMOTTI, F. (2008) Contro natura. Bari: Laterza.

TULLIO ALTAN, C. (1992) Soggetto, símbolo e valore. Milano: Feltrinelli. 